\title{
Retreat in the concept of health and medical education
}

\author{
D. N. Sinha \\ Formerly Professor and Head, Dept. of Anatomy, Government Medical College, Haldwani, Uttarakhand, India \\ *Corresponding Author: D.N. Sinha \\ Email: drdnsinha@hotmail.com
}

Received: $2^{\text {nd }}$ August, 2018

Accepted: $25^{\text {th }}$ August, 2018

\begin{abstract}
Reviewing the article of Prof Panagariya on Medical education and healthcare planning in present state. It is difficult to understand as to what planner says, what is motive, and when the phenomenon of implementation is not at right tract due to political instability and understanding. Moreover, the planning is politically criticizing the past system without giving any reason as to how this will be taken in governance in true humanitarian spirit for removing the suffering of the common people. Change in the name may not cause any value in this mission of medical education.
\end{abstract}

Keywords: Health, Medical education.

\section{Introduction}

The article "Threshold Renaissance Medical education is in desperate need of transformation NMC Bill can bring it about" was published in TOI on $10^{\text {th }}$ January 2018 by Prof. Arvind Panagariya. The Writer is Professor of Economics at Columbia University. He was chief of planning commission and had shown interest in medical education and health care.

He noticed collapse of the medical education under the name of Medical Council of India. Prof Arvind should have seen the history of medical education in India which was earlier much strong. If there is headache in the system, you cannot cut the head for its cure. It is not completely bad only its process which have been politically deranged due to corporate involvement and people engaged in it, are some how responsible to save guard the interest of the political agenda. Earlier the system went well and produced many doctors who are serving in USA, UK and other countries. They have made remarkable contribution in the Medical sciences. I do not know why the Columbian economist did not take initiative to improve the Indian medical Economic. There are several reputed Nobel laureate economists, but there is no improvement in world economics. However the countries are spending largest money for the purchase of defence equipments, nuclear arsenals, than how could you think that the world order of peace, justice, equality and brotherhood would develop to remove the poverty and disease in the regions. And who are the countries responsible for it? Must be known to all.

Nothing is possible to improve in medical education even after the bill is being passed. Why so? Never realized by the planners. Mere change in the name of medical council could not do anything as speculated by learned economist of Columbia. India is highly populated country and the American economist cannot bring any suitable planning to improve the health care system and medical education in India. The
American planning cannot do unless the same amount of money which they spent in America are being utilized by health care and medical education in India. There is no need of legislature to bring the change in the name and introduce something which is not possible to carry forward for longer term unless the political interference is being removed to rectify the orders of system. System is good only the person who do play great role deranging the process of systems need to be cured. The problem is much at the site of implementation. Why Govt. allowed more emergence of medical colleges without knowing the infrastructure of the colleges? The manpower planning basically for teacher's shortage and suitability have been ignored without realizing the consequences in the fall of qualities of the standard. This has allowed corporate to take upper hand in health care delivery in view of lack of vision in health sectors. The corporate came with the latest technology and utilized our own product of medical profession and have become super in the medical education. The real teacher those who did more in medical education have been avoided and moreover they have never been consulted in framing the national issues on health. Moreover, the Govt. gives more importance to the corporate sectors and trust to invite people to improve the MCI. Why so? ${ }^{1}$

This is in same spirit, how the East India Company came to this country. Now there is no girth of MNC in any sectors and they are doing business at the cost of this country. Prof Arvind has not pointed out the corruption history of M.C.I. How could only be in M.C.I. when institutions in country are not free from corruptions. Economic corruption have already engulfed the systems. Planning is easy to be done without being involved in implementation. Even all that nothing is possible to improve in existing situations. Let us see the people interest where it is finally reflected. During formation of the MCI in the beginning more learned people were involved whose contribution were 
above any one. Prof Pangariya pointed out the broad philosophy of Ranjit Roy Choudhary but when I look to the past I do not find any difference. All the earlier committee's recommendation was superior, but the Govt. participation and much money is needed in right direction without distorting the basic principles on which MCI was erected, should have not been ignored. Recently more AIIMS have been added which is being organised by the same doctors who have been produced by the system of MCI, which is currently blamed. Prof Arvind finally gives credit to the parliament to prevent total collapse of medical education to bring renaissance in the field. In my opinion there is nothing short of collapse history, it is almost same as other institutions of the country but it has been blamed extensively without realizing its role in post independent India for the initiation and establishment of the premier medical education Institutions are serving the national health programme under the $\mathrm{WHO}$ and other international agency for the eradication of Polio and other diseases. Prof Arvind Panagariya again got published an article in the Times of India on $7^{\text {th }}$ March 2018 entitled "It's all in the "Design the Ayushman Bharat can be transformational it governance of public health care is attended".

Prof Panagariya has also stated that the design and implementation challenges facing NHPS are even greater. Hospital will have to inherent interest in pushing patient towards more expensive procedure or towards more expensive not even required. Any lack of clarity in delineating included and excluded procedures will become a source of abuse. Paper also coat the poorest of the poor seek private hospital care speaks volumes for their lack of confidence in public health care system Expert do not give high marks to existing insurance schemes either". Health care problem and policy needs a special attention because implementation never take place in present setup of human resource. Clinician, paramedical staff do not get adequate people for the treatment of patient in public hospitals. ${ }^{2}$

The economics of lower level of health care points out that infrastructures must be adequate, so that person to be treated need not to wait in front of hospital for simple reasons. The work culture as yet not improved due to political interference and disappointments. Complexity therefore persists. Change in policy may not give any advantage to the system unless system is improved at the humanitarian level.

\section{Conclusion}

Both the articles of Prof Panagariya on medical education interacts with present perspective in search of some solution in the Medical and health care delivery. In the last article he too realized why the implementation could not take place. It appears a retreat in objectives of scheme of the health care. Ground reality is different and have hidden agenda to be dealt at the political platform. Without puting a finger on a institution which has created the path of future programme of medical education in India. Prof Pangariya is appreciated for taking interest in health planning.

\section{Reference}

1. Sinha D.N. Disease-choose life span a health problem and medical education. Indian Journal of Clinical Anatomy and Physiology. 2017;4(2) 273-275.

2. Sinha D.N. Reform in MCI-A news of these days. Annals of International Medical and Dental Research. 2017;3(6):12(TI).

How to cite this article: D. N. Sinha. Retreat in the concept of health and medical education. Indian J Clin Anat Physiol. 2018;5(4):564-565. 